\title{
Spatial Proxemics: experiments and contributions of anthropological relationships in digital media
}

\section{SIGRADI2018 TECHNOPOLITICAS \\ xxii congresso da sociedade iberoamericana de gráfica digital 22th conference of the iberoamerican society of digital graphics 07|08|09|novembro|2018 iau usp | são carlos | sp br}

\author{
Caio Almeida \\ Universidade Federal de Juiz de Fora | Brazil | caioaugusto.arq@gmail.com \\ Guilherme Brandão \\ Universidade Federal de Juiz de Fora | Brazil | guilherme.loures@engenharia.ufjf.br \\ Fernando Lima \\ Universidade Federal de Juiz de Fora | Brazil | fernando.lima@arquitetura.ufjf.br

\section{Marcos Borges} \\ Universidade Federal de Juiz de Fora | Brazil | marcos.borges@engenharia.ufjf.br
}

\begin{abstract}
Proxemics was first defined by Edward. T. Hall as being the relations between non-verbal communications in a determined space. This paper aims to promote a theoretical interpolation between diverse study fields with new contemporary urbanism paradigms supported by technology and anthropological relations. In this optics, to provide a better understanding of possible characteristics within the proxemics theory can translate into a better spatial understanding and city improvement from an analysis methodology using digital tools.
\end{abstract}

Keywords: Proxemics; Architecture; Urbanism; Phenomenology; Digital space.

\section{INTRODUÇÃO}

Proxêmica é um termo elaborado pelo antropólogo Edward T. Hall em 1963, que trata do conceito das comunicações não verbais inseridas dentro da vida cotidiana. É um ramo teórico utilizado na psicologia e antropologia para descrever o espaço pessoal de indivíduos em um meio social. Hall (1971) estabelece quatro esferas diferentes de relacionamentos: íntimo, pessoal, social e público, de forma que a distância entre estes espaços pode variar de uma cultura para outra. "Os humanos são seres territoriais, as pessoas cotidianas reivindicam o espaço, constroem sobre ele, e assim, marcam seu território" (Hall, 1971; p. 59).

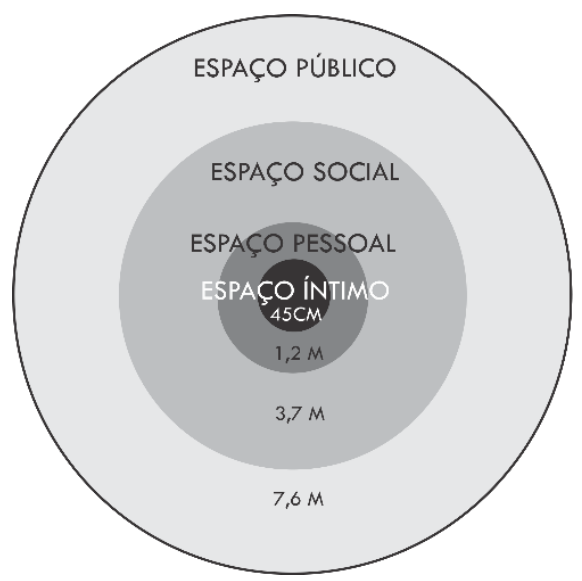

Figura 1: Distância e correlação dos espaços proxêmicos segundo Hall. Fonte: Autores.
No atual momento de urbanização, nota-se o surgimento de uma série de oposições que caracterizam mecanismos evolutivos em meios urbanos: incluindo passado e futuro, tradição e inovação, resistência e efemeridade, permanência e transição. Todas essas palavras passam a estar presente no discurso de evolução da sociedade e da cultura nas cidades.

Soma-se estes fatores as incertezas da atmosfera social, política e econômica das diversas partes interessadas, que mudam as decisões de planejamento ou funções antes estipuladas.

Todas essas questões apresentam-se como insumos complexos, dos quais se torna necessário uma negociação dessas dicotomias aparentes, ao invés de introduzi-las como polarizadoras, principalmente em formas que se apresentam opostas como a urbanização planejada em contraponto à informal, o crescimento de cima para baixo e o ascendente.

O desenvolvimento de métodos para avaliação e análise de diferentes cenários de crescimento e planejamento em relação a qualquer política do espaço proposto e suas consequências futuras, ganha então grande importância para que se tome decisões melhor embasadas, principalmente pelo fato desse sistema compreender atividades humanas com dinâmicas de espaço e tempo complexas.

Partindo então das definições desenvolvidas por Hall, esse trabalho realiza um método de pesquisa que parte do princípio das categorias de classificação do espaço 
por ele determinadas, e introduzindo o conceito de distância social, também conhecida como espaço corporal, do qual seu uso é o que podemos denominar de proxêmicas do espaço urbano, com o relacionamento entre os "nós da cidade" e as relações interpessoais, com itens que abrangem benefícios sociais diversos como: segurança, comunicação, áreas livres, habitação, engajamento e serviços.

\section{PROXÊMICAS DO ESPAÇO}

A análise das proxêmicas de um espaço podem ser utilizadas como afirmação das dimensões sociais que são tocantes ao espaço construído. De maneira em que à medida que a dinâmica das dimensões das interações sociais são integradas a uma concepção fenomenológica e a um design orientado, os planejamentos e futuros edifícios podem ser projetados e inseridos de modo que apoiem os contextos culturais e sociais locais de maneira mais eficiente.

De uma maneira simplificada, Proxêmica pode ser entendida como o estudo de meios nos quais os indivíduos fazem uso do espaço físico na interação entre estes indivíduos. Todo e qualquer organismo no universo tenta ocupar, cultivar, preservar e utilizar o espaço. Este processo de territorialização do espaço, difere de cultura para cultura (Hall, 1971).

Umberto Eco (1976) ao tratar de códigos linguísticos da arquitetura, apresenta conceitos semelhante ao que Hall classificou como proxemia, no qual aponta que a mesma é o estudo das distâncias entre os seres humanos. Sendo possível percebê-la como uma linguagem que não é dita, mas notada através de uma leitura destas distãncias e que poderia auxiliar a se projetar melhor as cidades e os objetos em que nelas se inserem.

Michel de Certeau (1998) realiza uma comparação da proxemia com uma linguagem, em que se lê em um segundo instante na vivência dos lugares e dos espaços, e a princípio realiza-se uma diferenciação entre mapa e percurso. Logo após, as demarcações que originam os lugares e espaços, e conclui com os relatos de espaço dentro das vivências das cidades.

Assim como a cultura de maneira geral, a proxemia é inclsuiva, portanto é importante ter algum meio para que possa ser explicitada.

Existem três áreas fundamentais com as quais os especialistas no campo categorizam Proxêmicas:

\section{Distância}

2.Espaços

3.Modos de comportamento e percepção

Segundo Hall (1971), as proxêmicas tratam com eventos estruturados e em movimento com conceitos de cinesia e linguagem. Essses conceitos se traduzem em dois processos básicos dos quais tentou-se incorporar no método de análise proposto: (1) cadeias de ação, caracterizados por possíveis vetores de transformação e (2) quadros situacionais, que seriam as transformações consequentes às cadeias de ação propriamente ditas.

Merleau-Ponty (1971) teceu reflexões sobre a circularidade existente entre os vários sistemas que compôem um espaço urbano, e do esforço contemporâneo em não dicotomizar as partes constituintes do todo, mas sim, em considerar as interconexões que se realizam nas ações humanas e o ambiente vivenciado, com a cultura e com os processos sóciohistóricos.

Posto isto, é preciso que se trate as questões de uma forma holística, agregando fundamentação em diversas áreas do conhecimento que abordam desde questões econômicas e de engenharia, até geografia, sociologia, antropologia, psicologia e arquitetura. Contudo o que se observa na maior parte das proposições sejam elas de escala local ou regional, é uma setorização de respostas, que se mostram incapazes de lidarem com os fatores de uma maneira mais eficiente e qualtitativa.

Esse artigo busca assim, promover uma interpolação teórica entre campos psicológicos e filosóficos com os novos paradigmas de urbanismo contemporâneo que passam a tentar introduzir outros parâmetros inseridos em meios digitais.

\section{MÉTODO}

O método adotado parte de um trabalho experimental de pesquisa urbana fundamentado na conceituação de espaço interpretada por diferentes campos de estudo. Essa interdisciplinaridade entre várias áreas de conhecimento, sempre contribuiu com novos conceitos de espaço, diferentes do euclidiano tridimensional.

Durante a última década, um grande número de sistemas de apoio à decisão espacial foi desenvolvido para auxiliar os tomadores de decisão no campo da alocação de recursos e, em particular, questões de planejamento espacial (Geertman e Stillwell, 2009).

O objetivo do método da pesquisa apresentada neste trabalho destina-se a realizar o potencial de quantificar dados demográficos, sociais e culturais em uma equação paramétrica.

Nos últimos anos, as técnicas e tecnologias para o desenho paramétrico foram gradualmente e deliberadamente transferidas para 0 planejamento urbano, ou seja, para o projeto urbano em larga escala, argumentando que os sistemas permitem gerar rapidamente diferentes alternativas de projeto simplesmente alterando os valores de um parâmetro particular. e a geração de diferentes cenários arquitetônicos e urbanos a serem avaliados, facilitando a tomada de decisões durante o processo de criação. (Silva e Amorim, 2010). Para Hall (1971 p. 161), muitas das experiências realizadas nos demonstram que o espaço comunica.

O primeiro estágio do experimento foi a escolha de lugar da cidade em que a pesquisa foi realizada. Os critérios levaram em consideração o constraste da diversidade de usos e dos agentes envolvidos com o espaço bem como dinâmica social presente.

O método usado foi o de estudo comparativo entre áreas selecionadas dentro da malha urbana da cidade de Juiz de Fora. Por meio de uma pesquisa em campo, utilização de arquivos de sistemas de informação geográfica e design computacional generativo integrando todos os dados para a constituição de como cada uma das áreas 
selecionadas apresenta um resultado com a mensuração dos dados e das pesquisas locais para possíveis cenários de análise e transformação.

Os Sistemas de Informações Geográficas (SIG) são uma maneira eficiente e seletiva de armazenar e apresentar informações georreferenciadas, apresentando diversos tipos de dados geográficos e espaciais. Os SIG utilizam dois tipos de dados: dados espaciais e dados de atributos (Longley et al., 2005). Os dados espaciais descrevem a localização e a forma das entidades espaciais; os atributos são as propriedades dessas entidades espaciais. Ao usar o SIG como entrada para um modelo de otimização, as unidades de decisão estão relacionadas a entidades espaciais, no sentido de que escolhas devem ser feitas para usos da terra em cada localização espacial.

Com base nestes critérios, como atividade local diversificada, potencial de desenvolvimento e adensamento futuro e público heterogêneo, foram escolhidos bairros em que pudessem demonstrar determinados contrastes e a diferenciação da demarcação de usos e ponteciais levantados pela aplicação da ferramenta.

No presente estudo, os dados foram obtidos através de pesquisa local com usuários de forma semi estruturada, para coleta de pontos e parâmetros representando cada um dos componentes em questão (habitação, serviços, espaço público) e como cada um desses pontos geralmente representa algum atributo significativo (avenida, rua de maior importância, linha de transporte público, margem de cursos d'água). Sendo então mapeadas as áreas no espaço.

Desde o princípio, as informações foram obtidas de forma a compor um banco de dados sujeitos a serem utilizados na geração de geometrias para ocupação e análise do espaço.

As ferramentas utilizadas aqui foram o software Rhinoceros, bem como duas extensões dentro do aplicativo, sendo elas Una Toolbox e Grasshopper. A ferramenta de Análise de Rede Urbana (UNA Toolbox) fornece métodos para avaliação de distâncias, assebilidades e lugares ao longo de redes espaciais,

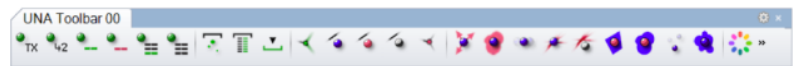

Figura 2: Barra de ferramentas da extensão para Rhino Una Toolbar. Fonte: Autores.

A ferramenta faz uso de "atributos" para fornecer propriedades a objetos de origem e destinos, com identificação por nome, número ou peso. Esses atributos reagem de forma semelhante às tabelas de atributos nos arquivos de forma dentro do ArcGIS.

A criação dessas "tags" de classificação de espaços, ou mapeamento de usos dos edifícios, dentro das métricas da extensão não permitem somente a análise espacial específica do funcionamento de uma rede determinada, mas também em incorporar em processo de desenho rápido.

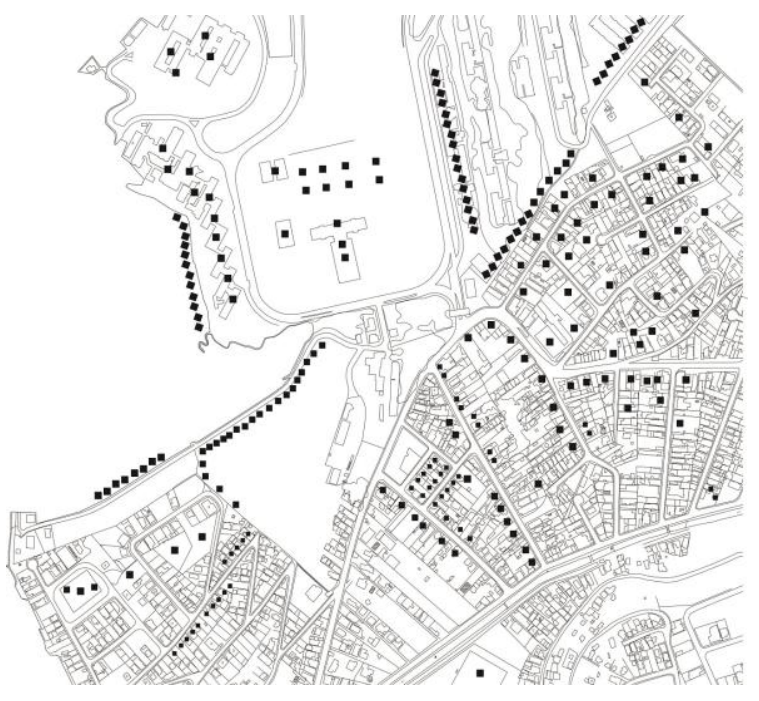

Figura 3: Colocação dos pontos, origens e usos obtidos com a ferramenta UNA. Fonte: Autores.

Por conseguinte, a temática deste trabalho consiste em duas partes principais: proxêmicas com um design de navegação com um terceiro fator organizador, que seriam as características levantadas em cada área analisada.

Desta maneira, o uso de recursos de modelagem generativa permitem a avaliação e construção do entendimento de cenários mais complexos e com base em informações e dados coletados.

Além das classificações de áreas do território pessoal mais comuns ao entendimento ligado a própria palavra como: espaço público, social, pessoal e íntimo, adaptamos as classificações de espaços de Hall para a elaboração dos mapas e das análises feitas em 2 categorias: Sóciofugal (espaços que são condutivos) e Sóciopetal (espaços que encorajam o convívio e solidariedade entre membros).

Com o arquivo shapefile (.shp) importado, fez-se uso da ferramenta adicionar curvas, que seleciona as curvas das quais foi construída a rede, podendo ser adicionado à seleção qualquer tipo de curva para integrar à rede linhas, curvas, arcos, etc. As curvas podem ser planas (2D) ou tridimensionais, desde que que elas compartilhem um nó final comum entre si.

Depois de adicionar curvas a uma rede, você pode continuar localizando pontos na rede. A maioria das funções analíticas na caixa de ferramentas da UNA usa locais discretos (pontos, edifícios, entradas etc.) como unidades de análise.

Existem três tipos de pontos de entrada na Caixa de Ferramentas do Rhino UNA: Pontos de Origem, Pontos de Destino e Pontos de Observação. Esta ferramenta adiciona localizações de origem à rede.

Depois de inseridos os pontos de acordo com as classificações, aplicou-se o processo de identificação de clusters espaciais nos pontos definidos nas redes. Eles são utilizados através da ferramenta UNA Toolbox para detecção de clusters de negócios, residenciais, espaços de preservação ou de qualquer outra agregação de eventos ao longo de redes. Esses clusters são definidos 
de acordo com dois inputs definidos pelo usuário: 1) o número mínimo de pontos que constituem esse cluster e 2) a distância máxima permitida da rede de cada membro do cluster até outro membro no mesmo cluster. Por exemplo, um cluster foi definido como um agregação que contém pelo menos 10 membros (eventos ou locais), em que a distância máxima de cada um desses componentes não seja superior a distância de $X$ metros em relação $a$ outro componente desse cluster.

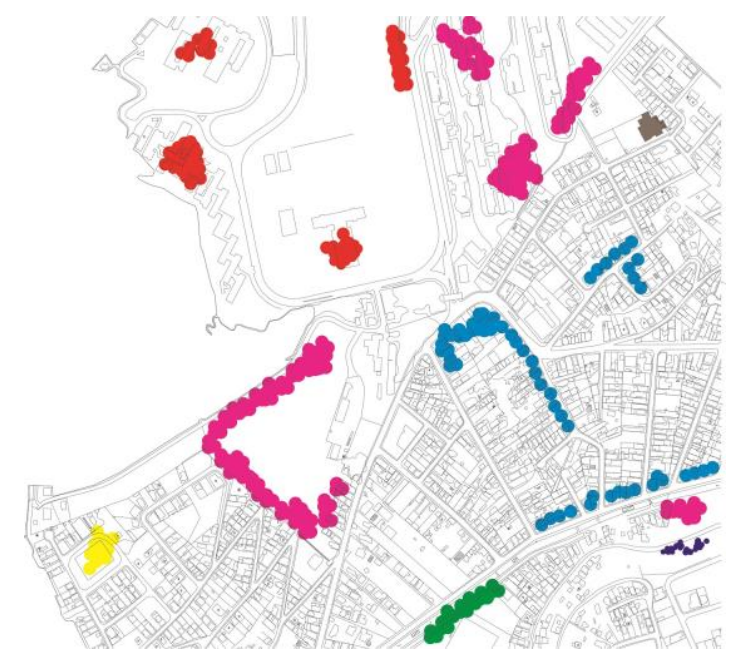

Figura 4: Mapa dos clusters (agregação de usos em determinada área) obtidos com a ferramenta UNA. Fonte: Autores.

O caminho seria a distância do tratamento urbano que edifica o nó, esse nó seria um ponto de interesse arquitetônico, uma necessidade ou um propósito geral na área.

Outra ferramenta da extensão usada foi a Service Area (Área de serviço), que seleciona ou copia os pontos de destino e os segmentos de caminho que estão dentro de um raio de rede de origem. A ferramenta pode ser usada, por exemplo, para selecionar todos os espaços públicos (destinos) que caem dentro de um raio determinado de um conjunto de pontos de ônibus ou nùmero de residências por área (origens).

A figura 5. demonstra os resultados que a Service Area gera através dos pontos de entrada de espaços públicos, demarcados na cor verde para todos os edifícios circundantes. Os edifícios com a cor vermelha e os segmentos de rua denotam quais destinos podem ser atingidos dentro de um raio de $500 \mathrm{~m}$ da rede a partir das origens dadas.

As análises obtidas através do uso desta ferramenta tiveram a importância metodológica de obter os mapas de maneira estruturada e bem informada de forma rápida e com manipulação de diversos parâmetros, dando suporte a uma tendência denominada urbanismo de informação

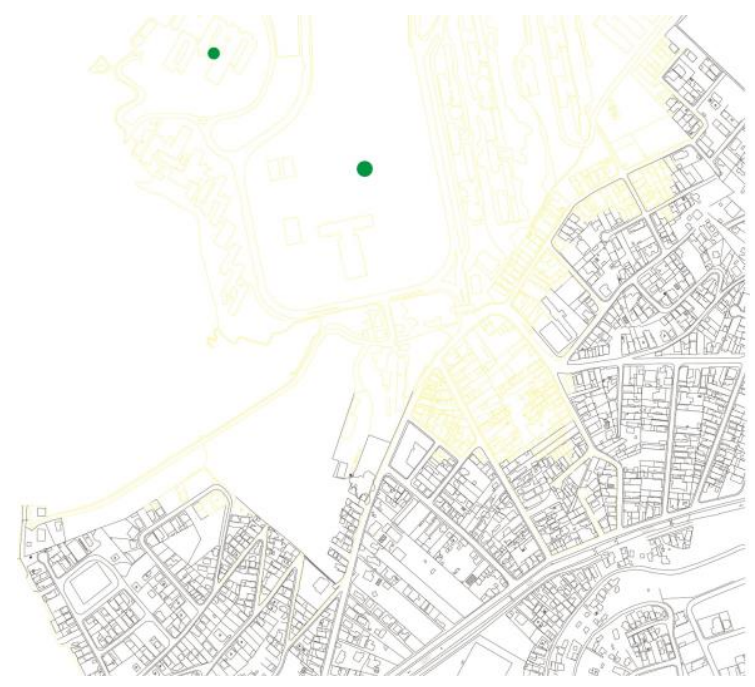

Figura 5: Mapa com o raio da Service area (área de serviço) obtido com a ferramenta UNA. Fonte: Autores.

O urbanismo da informação é definido como um método heterogêneo que busca formas urbanas lógicas e analisa sua importância através da educação de design urbano. O método é ampliado explorando, coletando, analisando e visualizando informações urbanas. Esse conceito baseia-se na pesquisa colaborativa e foca na integração de SIG com teorias e práticas de urbanismo paramétrico, onde o foco é a coleta de dados, análise de padrões, visualização e modelagem espacial. Perceber esses comportamentos na estruturação e planejamento de uma cidade e de seus espaços, tornam-se instrumentos que podem ser utilizados para visualização e formação de estratégias de projeto. A proxêmica, como bem informa Hall (1971) é uma ciência de síntese e contextualização.

A proxêmica, definida como o uso e a percepção do espaço social e pessoal, e em como os arranjos espaciais determinam a logística do uso e da comunicação de determinado território, que auxiliada com ferramentas digitais e paramétricas presentes no discurso contemporâneo de produção arquitetônica e urbanística tendem a contribuir para investigações e proposições que possam melhor compreender o espaço vivenciado e traçar futuras mudanças.

Projetar com o auxílio de tecnologia, ambientes sociais e colaborativos necessitam de uma percepção do contexto físico e social das pessoas e a interação entre elas e das interações situadas.

Em um último momento, com os pontos determinantes estabelecidos pelas análises efetuadas e agregando os benefícios das ferramentas na geração das mesmas, foi explorado com o uso de Grasshopper, a obtenção de possíveis soluções urbanas na geração de formas urbanas, que tiveram como construção da lógica vetores baseados nos pontos, agentes e vetores.

Avaliação do espaço de preencher diversas necessidades e aptidão a apropriação, e distância social, que regulamente distâncias entre diferentes grupos, por diversos tipos de fatores. 


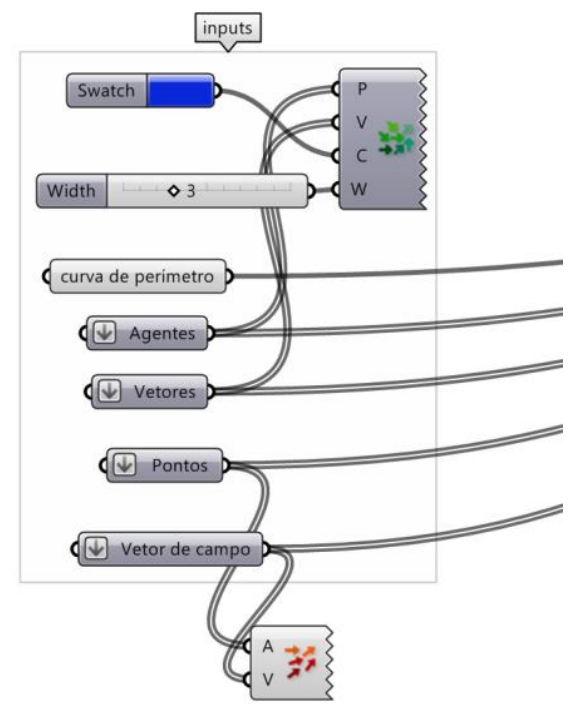

Figura 6: Interface do Grasshopper obtido com parte da lógica para obtenção de possíveis formas locais. Fonte: Autores.

Pode-se dizer que o método da pesquisa é uma função da faceta particular sob uma análise do presente momento e do qual pode-se exigir o envolvimento de diversas disciplinas, como estudos sociais e programação.

Ainda que como o Hall (1968) descreva "o estudo da cultura no sentido proxêmico é o estudo do uso das pessoas do seu espaço perceptivo em diferentes estados emocionais durante diferentes atividades,em diferentes relações, configurações e contextos. Nenhuma técnica de pesquisa única é suficiente para investigar a complexidade desta multiplicidade de assuntos dimensionais.

\section{RESULTADOS}

A exploração da diagramação espacial, realizada através de uma modelagem digital, demonstra em como fenômenos urbanos e padrões geoespaciais podem ser interpolados em formas parametricamente controladas, e que posteriormente, podem ser traduzidas em soluções de design e planejamento.

Nos modelos obtidos, as tentativas de integração de parâmetros não necessariamente geométricos no processo de fabricação de formas teve como resultado diversos resultados conceito.

A incorporação presente de diversos campos teóricocientíficos no pensamento e análise do comportamento urbano não é algo recente. Importantes figuras do pensamento social, antropológico e filosófico como Merleau Ponty, Luce Irigaray, Claude Lévi-Strauss, Georg Simmel entre outros realizaram extensas pesquisas na relação entre abordagem e percepção humana e condição urbana. O fator de descoberta no presente estado, é em tecer como essas inferências teóricas, culturais, políticas, sociais tendem a ser um desafio intelectual presente frente as práticas computacionais que passam a assumir cada vez mais esses direcionamentos.

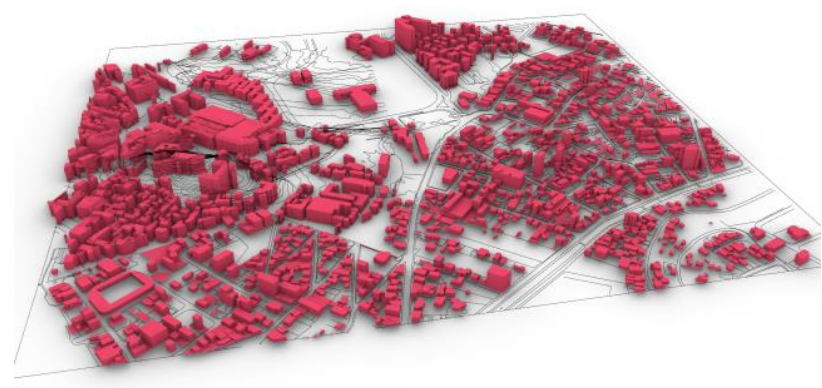

Figura 7: Resultado obtido com o uso do Grasshopper. Fonte: Autores.

Os modelos foram expressados manipulando o zoneamento, vias de circulação e os vários tipos de construção.

Tal como apontou Lefebvre (1996), a especialização das ciências tornou as respostas cada vez mais segmentadas, dentro do urbanismo isso se torna axiomático quando diversas questões são tratadas de forma individual por agentes diferentes, como se uma mesma resposta não fosse capaz de solucionar mais de uma delas, sobrepondo esforços e aumentando o grau de dificuldade e distanciamento da gestão do espaço urbano.

Os resultados tiveram como objetivo a transição de modelos de conceito tipo para modelos do tipo processo. Isso implica em um resultado que fosse consequente a efeitos observados e analisados sobre elementos interligados (objetos, materiais, dados). Conclui-se como resultados, a contribuição para o conhecimento de possíveis diálogos entre a cultura da cidade no seu sentido proxêmico, ou seja, na relação que as pessoas estabelecem com a cidade em diferentes estados, configurações e contextos, e em como essas alternativas propõem perspectivas abertas e suscetíveis ao envolvimento de muitas disciplinas, que tendem progressivamente a contribuir com o assunto em questão.

\section{CONSIDERAÇÕES FINAIS}

Para Eco (1976), a arquitetura e o urbanismo não podem renunciar de compreender os fatores da proxemia, pois não seriam projetados espaços coerentes para os habitantes, sendo necessário estabelecer uma equipe interdisciplinar, onde sociólogos, antropólogos, entre outras categorias profissionais, poderiam contribuir para a projeção de problemas das grandes cidades.

Uma das proposições futuras seria a de compreender quais as contribuições que podem ser feitas por meio de uso de ferramentas paramétricas e construção de modelos efetivos de compensação do território e do uso local do espaço, ou ainda a distribuição do layout de serviços dentro de um território, com base nas necessidades reais dos usuários e superando padrões impostos por padrões de urbanismo e planos diretores para regulamentação qualitativa de espaço baseadas em mapas e estudos comparativos.

Uma outra possibilidade, seria a simulação de cenários alternativos apoiados em uma escolha de tipologias ou densidades de crescimento e uso diversos para 
transformações urbanas. Ou ainda, a otimização de infraestruturas existentes.

Ainda assim, embora muitas pesquisas venham sendo realizadas em sensoriamento, adaptação e na própria filosofia do conceito de "contexto" com abordagens computacionais para projeto de maneira bem latente na prática de arquitetura e urbanismo, ainda permanecem poucos conhecimentos teóricos baseados sobre os motivos, de que pelo ponto de vista de experiência do usuários, alguns projetos funcionam bem e por que outros não e maior partes das correntes permanecem não teorizadas.

Portanto, o viés tecnológico, seja na prática e na teoria apresenta um dos desafios intelectuais mais profundos para este atual momento do urbanismo: descobrir as implicações antropológicas, culturais, políticas, sociais e urbanas dessas novas práticas computacionais, e em como conciliar o discurso sensível a um crescimento coordenado e aberto as diferentes possibilidades e particularidades.

\section{AGRADECIMENTOS}

Agradecemos à Universidade Federal de Juiz de Fora e à CAPES pelo suporte concedido.

\section{REFERÊNCIAS}

Geertman, S., Stillwell, J. (Eds.) (2009). Planning Support Systems: Best Practice and New Methods. New York: Springer.

Hall Edward T (1971). The Hidden Dimension. University of Chicago, Chicago.

Hall Edward T. et al. (1968). Proxemics Comments and Replies. Current Anthropology, 9.

Lefebvre, Henri (1996). Writings on Cities. Translated and edited by E. Kofman and E. Lebas. Oxford: Blackwell.

Longley, P., Goodchild, M., Maguire, D., Rhind, D. (2005). Geographic Information Systems and Science. New York: Wiley.

Merleau-Ponty, M. (1975). A estrutura do comportamento (J. Corrêa, Trad.). Belo Horizonte: Interlivros.

Silva, R. C.; Amorim, L. M. E. (2010). Parametric urbanism: emergence, limits and perspectives of a new trend in urban design based on parametric design systems. Trans. Anja Pratschke. In V!RUS. 3. São Carlos: Nomads.usp. Retrieved from http://www.nomads.usp.br/virus/virus03/submitted/layo ut.php?item $=2 \&$ lang $=$ en .

UNA TOOLBOX - HELP -version 5.10.10.20 r5rs10 - Urban Network Analysis Toolbox for Rhinoceros 3D - City Form Lab - Harvard - City Form Lab, Andres Sevtsuk; Raul Kalvo; The Urban Network Analysis Toolbox for Rhinoceros 3D is distributed by the City Form Lab and can be used under the License of Creative Commons Attribution-NoDerivatives 4.0 International. Retrieved from : http://creativecommons.org/ licenses/by/4.0/legalcode; 2015. 